\title{
Interactive Groups: Examining and Interrogating Issues of Heterogeneity and Accountability
}

\author{
Gail Frost \& Maureen Connolly \\ Brock University
}

Teachers and learners alike bring past experiences into present teaching and learning contexts. Group work is an experience that carries equal measures of joyful anticipation and mournful trepidation. Learners typically experience group work as an uneven distribution of time, competence, and accountability, and seem to have lingering memories of one or two people doing all the work in order to salvage a respectable grade. While students must understand the group process when they work in problem-or inquiry-based teams, we think the onus should also be on the instructor to devise methods of equity and accountability, which address the aforementioned justifiable fears. Our paper will describe several strategies we have used to anticipate and offset the inevitable tensions and contingencies inherent in group work.

$\mathrm{M}$ y (Gail's) decision to teach a class using a problem-based learning format required taking a closer look, with the aid of our Centre for Teaching, Learning, and Educational Technology, at group work and how to manage it in a way that encouraged and reassured students, and also stayed true to the basic tenets of problem-based learning. This comment from a student in my class seems to summarize the feelings of many students:

I enjoy a course where I am required to attend class, and complete assignments on my own and during my own time. I have a hard time relying on others to contribute fully to group assignments, as I have had bad experiences in the past. I like to complete assignments on my own so that I know they will be done properly and handed in on time.

Do students' concerns about group work reflect a genuine preference for another style of learning, or are they actually the result of past experiences with poorly managed groups? It has been helpful for me to take the time, at the beginning of a course, to have students identify their preferred learning environment and learning strengths. Surprisingly, many students have not thought about this in an organized way. This can be done by using inventories or 
questionnaires designed specifically for this purpose, such as the Kolb Learning Styles Inventory or the VARK Questionnaire (Kolb, 1984, 1999; Fleming $\&$ Baume, 2006). Expand on this exercise by having students place themselves on a line representing the continuum between lecture-based classes on one extreme to small group, participatory classes on the other. Ask them to explain why they placed themselves where they did, emphasizing that there is no right answer to this exercise. Lecture-based courses with a reading list, midterm, and final exam are 'safe' for those students who are fearful of not knowing the answer if they are called upon. With group work, problem-based learning may be seen as threatening and intimidating.

Have students write about whether they agree or not with the results of the learning strengths inventory or questionnaire. They will need to give some thought to their own learning preferences to be able to agree or disagree. When these activities are done before forming groups, they help students to appreciate the diversity of thoughts and actions, which will undoubtedly be present in their group, and understand that this can be an advantage when working on a problem together, as it guarantees different points of view.

Many of the management issues related to group work centre around accountability, i.e. is everyone doing their share of the work? Using a 'log book' to keep a record of group meetings can be helpful. Have students record the date and time of meetings, who was there, who was late, who sent regrets, and who was absent without notice. Have group members check in and share news or information. Review the minutes from the previous group session and address old business by having students update what they've done or found since the last meeting. Address new business and what must be done next, by whom. Set timelines. Determine the next meeting time and place. End by giving everyone a chance to make a last comment or suggestion. The log book helps to support or refute complaints from group members about another member not 'pulling his/her weight.' It also provides a record of each member's responsibilities for the next session, for example, information to be found, person to be contacted, or data to be checked.
Use roles such as facilitator, recorder, mood minder, and time keeper to organize the group sessions and provide a way for quiet or shy students to participate. The 'voice' of their role will gradually be replaced by their own voice, sharing more of their own ideas as they gain confidence within the group. Rotate the roles for each meeting.

The log book can be used to record and store material relevant to solving the problem; however, a recent experiment using on-line Wikis (a website that allows visitors to make contributions or corrections) for each group has shown me that this option may be better. Students can add material to the Wiki any time that they are on-line, and they like the idea of being able to work on their own schedule. It's possible to monitor individual contributions to the Wiki and this can serve as a means of assessing participation. Strategies like the log book and the Wiki make distribution of work and accountability for work done more transparent to all group members. When supplemented by the information about learning styles, group members can also come to appreciate the different pacing and processing preferences of each group member and deal with them as learning preferences rather than deliberate avoidance and sabotage of the group task. Once group members realize that tasks can still be completed, even though the means to completion may be varied, they are more likely to trust each other and be less anxious about having to control everything. This can also lead to more creative and resourceful problem solving and thinking relative to the task.

Group work can also involve end products that are non-traditional. I (Maureen) give a groupbased assignment I call 'not a paper.' It can be any format as long as it can be shown as an interactive display and is not text dominant. Here, students pool different talents, competencies, and ideas to create a product different from their regular presentation and paper-based formats. I have seen everything from dramatic performances to puppet shows, sculpture to dance, websites to talent cafés. I am always delighted by the ways students can learn to run when there is an open space before them.

In my (Gail's) class, students complete two evaluations at the end of term. Each group evaluates 
the presentations of all the others, using a grading template and giving specific feedback, which is elicited by asking the group to complete two phrases: "One good idea from your presentation was..." to encourage positive comments and "Did you consider..." to encourage constructive criticism. The second evaluation has each student complete an anonymous within-group distribution of marks form to tell me how to split up the mark their group has earned among the group members. This anonymous evaluation assesses contributions in three areas: discussion/planning/decision-making, information gathering/explanations, and presentation contribution. Other approaches to assessing group work include anonymous peer and self evaluation submitted by writing a letter to the instructor. Group assessment is also an intriguing format, especially in an 'in class, single use' activity. An example from my (Maureen's) class in developmental games involves the following: all 36 students in the class indicated distaste for the usual presentation of a game that they work on as a group outside of class time, in order to present it in class to their peers. I decided to get the whole experience - group selection, game selection, practice, and presentation into one, three-hour class period. Students arrived and drew a letter from a large envelope, which contained six A's, B's, C's, D's, E's, and F's. The similar letters formed a group of six. Each group sent an emissary to choose one game from one envelope, and another game from another envelope. The task was to create a hybrid game from the two chosen. All groups had an hour to plan and practice. Then, each group presented its hybrid game and was assessed. Students overwhelmingly supported this approach. They liked the random groups and game selection, the equal preparation conditions, and the fact that the assignment was finished within one class session. I have also used this format for written assignments with equal success.

We have shared several of our approaches to managing group work in the hope that it will encourage instructors to consider using group work in assignments and assessment. We hope that instructors will use our experiences to guide their decisions about planning, implementing, and monitoring group work with learner heterogeneity and transparent accountability in mind.

\section{References}

Fleming, N. \& Baume, D. (2006). Learning styles again: VARKing up the right tree! Educational Developments, 7.4, 4-7.

Kolb D. (1984). Experiential learning: Experience as the source of learning and development. New Jersey: Prentice-Hall.

Kolb D. (1999). The Kolb learning style inventory. Boston: Hay Group.

\section{Biographies}

Gail Frost is an Associate Professor in the Department of Physical Education and Kinesiology at Brock University in St. Catharines, Ontario. She teaches courses in musculoskeletal anatomy, prevention and care of injuries, and therapeutic exercise. Her research includes studies to: 1) assess the effectiveness of clinical rehabilitation interventions; and 2) implement problem-based learning in her teaching.

Maureen Connolly is a Professor of Physical Education and Kinesiology, is cross appointed to the Department of Child and Youth Studies, and is a contributing faculty member in the Centres for Applied Disability Studies, Women's Studies, and Adult Education, and in the Faculty of Education at Brock University, St. Catharines, Ontario. She is presently in her last term as Director of the Centre for Teaching, Learning, and Educational Technologies. Her interests have led her to collaborate with community partners in a variety of teaching and scholarly projects, such as the Summer Movement Camp for children and youth with Autism Spectrum Disorder and the Special Needs Activity Program. 